Check for updates

Cite this: RSC Adv., 2017, 7, 37887

Received 15th May 2017

Accepted 17th July 2017

DOI: $10.1039 / c 7 r a 05468 \mathrm{~h}$

rsc.li/rsc-advances

\section{Recent advances in the rational design of copper chalcogenide to enhance the photothermal conversion efficiency for the photothermal ablation of cancer cells}

\begin{abstract}
Chenglin Yan, (D) Qiwei Tian (D)* and Shiping Yang (D) *
Copper chalcogenide nanoparticles have received increased attention as photothermal agents due to their low cost and easy preparation. Nevertheless, the underdeveloped photothermal conversion efficiency of copper chalcogenide has limited its further application for cancer therapy. Thus, enhancing the photothermal conversion efficiency of copper chalcogenide through rational design is desired. In this review, we have discussed three kinds of rational design and a mechanism for copper chalcogenide to enhance the heat conversion efficiency in detail and briefly introduced their application in photothermal therapy. First is the design and synthesis of the superstructure nanoparticle agents to enhance photon refraction. Then, tuning the degree of copper deficiency enhances the localized surface plasmon resonance absorption caused by copper chalcogenide. The rest is constructing the hybrid composite to further enhance the localized surface plasmon resonance absorption through the coupling effect of different functional units. Despite higher photothermal conversion efficiencies and better therapeutic effects for cancer achieved through rational design, there still exists a challenge to be addressed, as well as promise for rational design facing the keen research and discuss before clinical applications of copper chalcogenide.
\end{abstract}

\section{Introduction}

As we all know, cancer and malignant tumor are the leading causes of death worldwide. ${ }^{1}$ Over the past few decades,

The Key Laboratory of Resource Chemistry of Ministry of Education, Shanghai Key Laboratory of Rare Earth Functional Materials, Shanghai Municipal Education Committee, Key Laboratory of Molecular Imaging Probes and Sensors, Shanghai Normal University, Shanghai 200234, China. E-mail: qiweitian@shnu.edu.cn; shipingy@shnu.edu.cn nanotechnology for the detection, ${ }^{2,3}$ diagnosis ${ }^{4,5}$ and treatment of cancer ${ }^{6}$ and other diseases, has undergone rapid development and innovation. Along with the improvement of the therapeutic progress and prospect, significant efforts have been devoted to exploring the improved therapy method, ${ }^{7-9}$ expecting to achieve better therapeutic outcomes and minimal side effects or physical pain towards the ultimate aim. Thus, except for traditional chemotherapy, photothermal ablation therapy has captured increasing attention, owing to its minimally invasive nature. ${ }^{10}$

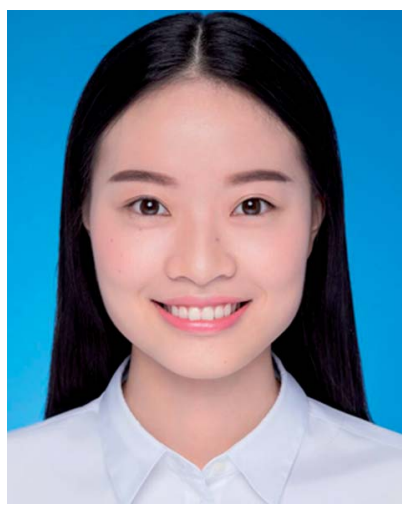

Chenglin Yan received her $B E$ degree from Shanghai Normal University in 2012. She is now a master's degree candidate in Prof. Shiping Yang's group. Her current research directions include nanomaterial-based cancer detection and photothermal therapy.

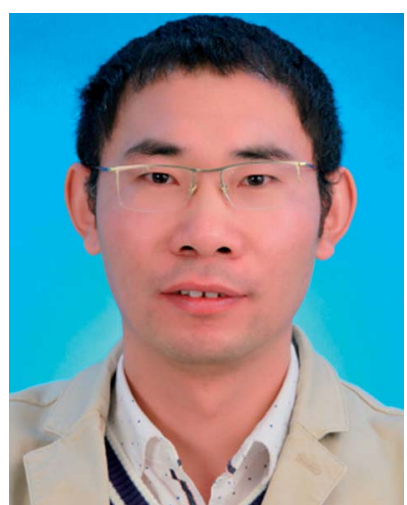

Qiwei Tian obtained his Ph.D. degree from materials science, Donghua University, China, in 2012, and worked as a postdoctoral fellow at King Abdullah University of Science and Technology during 2012-2015. He is currently working as an associate professor in Shanghai Normal University and is focused on developing multifunctional nanomaterials for cancer theranostics. 
Specifically, photothermal ablation therapy, induced by laser in the near-infrared (NIR 700-1100 nm) region, ${ }^{11,12}$ gradually holds an important status in the nanotechnology therapy field because of the low scattering and small absorption of NIR light by tissue and blood and the ability to reach several centimeters inside biological tissues. ${ }^{\mathbf{1 3 , 1 4}}$ Subsequently, a key determinant in the applications of photothermal ablation therapy is exactly the exploitation of novel photothermal agents, which possess attractive advantages such as strong NIR absorption ability and/ or excellent photothermal conversion efficiency (PTCE). ${ }^{15-17}$ Generally, photothermal agents will produce the photothermal coupling effect, which gives rise to the absorption of NIR light, and then results in the transformation to thermal energies that will burn out nearby cancerous cells. ${ }^{18}$ To paraphrase the great importance of photothermal agents, higher PTCE will equally induce the death of cancerous cells with shorter irradiation time, smaller concentration of nanoparticles (NPs), or lower power density of the NIR laser to ensure the safety of healthy tissues in the human body. ${ }^{19}$

Copper chalcogenide is a p-type semiconductor and has been widely explored in energy, ${ }^{\mathbf{2 0 - 2 3}}$ catalysis-related applications, ${ }^{\mathbf{2 4 2 5}}$ and most especially in tumor theranostics. ${ }^{\mathbf{2 6 - 2 9}}$ Compared with carbon, ${ }^{30-33}$ noble metal, ${ }^{34-36}$ and organic materials, ${ }^{37-40}$ the merits of using copper chalcogenide NPs in the diagnosis and therapy of disease include not only the low cost and toxicity, but also the intrinsic strong NIR absorption, rendering a promising alternative for photothermal ablation of cancerous cells. ${ }^{\mathbf{4 1 , 4 2}}$ However, it is noted that the unsatisfactory PTCE limits their applications in photothermal therapy to a large extent; ${ }^{43}$ for instance, CuS NPs with an ultrasmall size of $\sim 3 \mathrm{~nm}$ require increased laser power intensity or particle concentration to obtain the same therapeutic result due to the low PTCE. ${ }^{43}$ According to the Safe Use of Lasers of the American National Standard, to cause sufficient death of cancerous cells, the excessively small CuS NPs require as high as 16 and $24 \mathrm{~W}$ $\mathrm{cm}^{-2}$, which is $\sim 48$ and 72 times higher than the conservative limit $\left(\sim 0.33 \mathrm{~W} \mathrm{~cm}^{-2}\right)$ of the laser intensity setting for human skin exposure..$^{\mathbf{4 4 5}}$ Thus, it is important to design and synthesize copper chalcogenide NPs which are capable of enhancing PTCE particularly in the photothermal therapeutic field.

As usual, for the simple purpose of enhancing PTCE, three routes of designing copper sulfide NPs can be classified. The first is tuning the structure of the isolated nanoparticle to

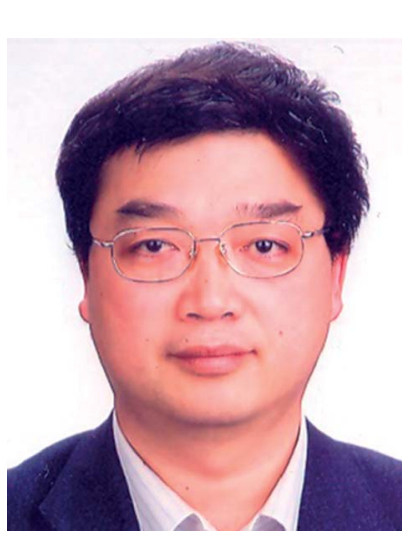

Shiping Yang is a Professor of the Key Laboratory of Resource Chemistry of Ministry of Education, Shanghai Normal University, P. R. China. He received his $P h D$ in Sun Yat-Sen University, $P$. R. China in 2000. His research interest is in the fields of biomedical applications of nanomaterials for novel biomedical imaging and cancer therapy. enhance photon refraction, coupling with stronger NIR absorption. Or by changing the synthesis condition to regulate the isolated nanoparticle to assemble into a different structure, leading to enhanced NIR absorption. The second is synthesizing non-stoichiometric copper chalcogenide NPs. And the rest is constructing the composite bimetallic nanomaterial. In this short review, we will provide an overview of the chemical mechanism of rational design for copper chalcogenide to enhance the heat conversion efficiency and their biomedical application for photothermal ablation of cancerous cells.

\section{Typical synthetic procedures for copper chalcogenide}

In general, it is paramount to properly manage the morphology, size and phase of NPs, which play vital roles in their optical and electronic properties. ${ }^{46}$ Specially, the absorption of copper chalcogenide is more dependent on their size, morphology and phase. ${ }^{47}$ In the past few years, several methods, such as hydrothermal method and solvothermal method, ${ }^{48}$ thermal decomposition $\operatorname{method}^{\mathbf{1 9}}$ and hard template method, ${ }^{\mathbf{4 9}}$ have been developed to control size, morphology and phase of copper chalcogenide. And we will introduce how to use the three main synthesis approaches for copper chalcogenide in this section.

\subsection{Hydrothermal method and solvothermal method}

Hydrothermal method ${ }^{50}$ and solvothermal method ${ }^{51}$ are the two most frequently used preparation techniques in the synthesis of copper chalcogenide NPs due to their high efficiency and simplicity. They are both synthesized in a high pressure reactor, the only difference is that the former uses an aqueous solvent, and the latter uses a non-aqueous organic compound as the solvent in the process of reaction. ${ }^{52}$ For these two reaction methods, it is easier to control the growth direction and morphology of nanocrystals by simply tuning the temperature, reaction time and surfactant. At present, a variety of copper chalcogenide nanocrystals with different morphology have been obtained by these two methods. The flower-like CuS was synthesized by our group through the hydrothermal method using PVP as the surfactant. ${ }^{48}$ In the study of Zhao et al., ${ }^{53}$ nanowires, nanotubes and nano-sized vesicles of copper sulfide were obtained by hanging the copper ligand at a lower temperature $\left(90{ }^{\circ} \mathrm{C}\right.$ to $\left.110^{\circ} \mathrm{C}\right)$ with an organic amine-assisted. High-quality isolated crystal $\mathrm{Cu}_{2-x} \mathrm{Se}$ nanosheets and nanodisks were prepared by Zhang et $a l .{ }^{54}$ through a green and simple solvothermal method using paraffin oil as a solvent. For solvothermal and hydrothermal methods, they are relatively simple processes, and more importantly, the nanocrystals obtained by these two methods have good crystal structure and different morphologies of nanocrystals can be attained by only changing part of the reaction conditions. However, large size and wide size distribution ${ }^{19}$ of copper chalcogenide synthesized by both methods limit their future biomedical application. 


\subsection{Thermal decomposition method}

The thermal decomposition method is based on copper precursor, $\mathrm{X}=\mathrm{S}$, Se, Te precursor, and long-chain hydrocarbon compounds (oleic acid, oleylamine, octadecene and so on) as the surfactant and solvent, using the metal organic chemistry mechanism to prepare chalcopyrite nanocrystals under the condition of anaerobic water and high temperature $(T>200$ $\left.{ }^{\circ} \mathrm{C}\right) .{ }^{55-57}$ And subsequently, by instantaneous nucleation under high temperature condition and further heat treatment process, copper chalcogenide nanocrystals with good crystallinity and homogeneous dimension are obtained. The Kolny-Olesiak group were able to synthesis uniform, high-quality $\mathrm{Cu}_{2} \mathrm{~S}$ nanorods with octadecene as a solvent in the process of pyrolysis, and by controlling the nucleation temperature, they achieved nanorods with different radial ratios. ${ }^{58}$ Due to faster growth speed of the crystal nucleus at the higher temperature, more lattice imperfections will be formed. Thus, most of the copper chalcogenide nanocrystals achieved by the thermal decomposition method are non-stoichiometric $\left(\mathrm{Cu}_{2-x} \mathrm{~S}\right)$ nanocrystals with deficiency, which brings about localized surface plasmon resonances (LSPRs) that resulted in tunable NIR absorption. Various shapes of $\mathrm{Cu}_{2-x} \mathrm{~S}$ nanocrystals, such as nanorods and nanosheets have been prepared by Korgel et al. ${ }^{59}$ Also in our previous studies, we succeeded to synthesize some kinds of non-stoichiometric copper chalcogenide with strong NIR absorption. ${ }^{19,60}$

\subsection{Hard template method}

The sacrificial templates method, in which the template is also used as the precursor, is an effective approach to synthesize the nanostructure materials, ${ }^{\mathbf{6 1 , 6 2}}$ especially for the hybrid nanostructure. For copper chalcogenide NPs, it is difficult to prepare the hybrid nanostructure directly, due to the issue of large lattice mismatch. ${ }^{63}$ In this regard, the sacrificial template is frequently utilized to prepare the copper chalcogenide hybrid nanostructure. Based on the sacrificial templates, there are two different mechanisms, one is cation exchange ${ }^{63}$ and the other is the Kirkendall effect, ${ }^{64}$ which were developed to prepare the copper chalcogenide hybrid nanostructure. The cation exchange method, ${ }^{65}$ in which the cation located in the nanocrystal template is substituted by another one in solution with the same template morphology, has been developed as a particularly powerful strategy to prepare nanocrystals with morphology and composition that are accessed difficultly by conventional methods. Depending on precise control of the stoichiometry over the reaction extent, the $\mathrm{Au} @ \mathrm{Cu}_{2-x} \mathrm{~S}$ hybrid nanostructure with flexible shape, crystallization and composition tailoring was prepared by Zhang et al., ${ }^{63}$ starting from the Au@CdS core-shell nanostructure (Fig. 1A). In the Kirkendall effect method ${ }^{66}$ the template, such as $\mathrm{Cu}_{2} \mathrm{O}$, reacts with the new molecular or ionic species (S, Se, Te precursor) by atomic or ionic diffusion and then a new shape and composition is formed. Using $\mathrm{Au} @ \mathrm{Cu}_{2} \mathrm{O}$ as a hard template, $\mathrm{Yu}$ et al. ${ }^{\mathbf{4 9}}$ and

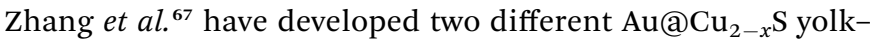
shell nanostructures (Fig. 1B).

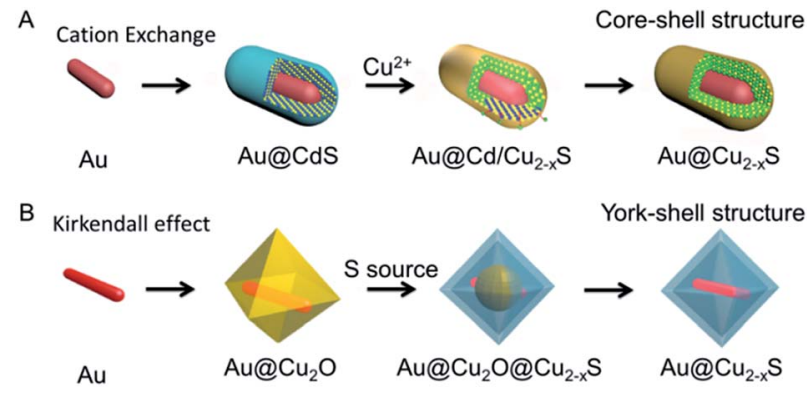

Fig. 1 Scheme of synthesizing the $\mathrm{Au}-\mathrm{Cu}_{2-x} \mathrm{~S}$ hybrid based on the template method. ${ }^{49,63}$ (A) Reprinted with permission from ref. 63. Copyright 2016 Wiley-VCH Verlag \& Co. KGaA. (B) Reprinted with permission from ref. 49. Copyright 2016 American Chemical Society.

\section{Copper chalcogenide with enhanced PTCE for cancer therapy}

Cytotoxicity limitation is a major concern for a novel welldesigned nanomaterial, particularly in the application of biomedical and clinical treatments. ${ }^{43}$ To be specific, to achieve the same therapy outcome, a higher concentration of nanomaterial will result in more efficient photothermal therapy to treat cancer cells or tumor, as an increasing number of nanomaterial particles will be absorbed by cancerous cells. In the meantime, high cellular uptake signifies that the cells accumulate a larger amount of nanomaterial, which leads to increased cytotoxicity. ${ }^{35,68}$ Aimed at the above contradiction between cellular uptake of nanomaterial and photothermal ablation of cancerous cells or tumor, recently, some groups began to throw light on how to improve the PTCE of the nanomaterial and further minimize the shortcomings brought from this contradiction as far as possible. In this section, we will introduce three routes of design and discuss the mechanisms on how to enhance the PTCE through the well-designed copper sulfide NPs in detail, as well as briefly present their applications in the photothermal ablation of cancerous cells.

\subsection{Nanostructure of copper chalcogenide}

Complex superstructures with enhanced and synergistic property, which are composited with simple building blocks, have attracted widespread interest owing to their great potential applications in biomedicine, ${ }^{69}$ energy storage ${ }^{70}$ and catalysis. ${ }^{71}$ Up to now, two different kinds of mechanisms have been proposed for the superstructure to enhance the PTCE. One kind is the building blocks of the superstructure aligned with photonic-crystal microstructures and/or the faceted end planes of well-shaped crystals, showing their ability to be utilized for good laser-cavity mirrors, which helps to effectively improve light absorption. ${ }^{48}$ The other kind is the superstructures that greatly influence the electronic structures of nanomaterials and significantly improve the molar extinction coefficient in the NIR region. ${ }^{72}$ For the photothermal agents, the more light is absorbed the more heat will be generated. Thus, constructing a superstructure for CuS NPs is a simple and effective method to 


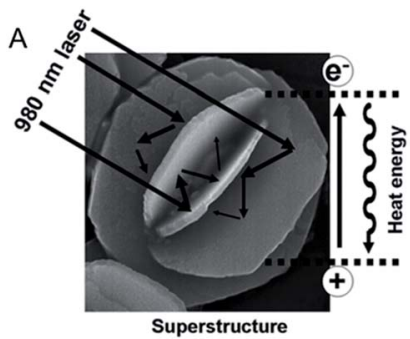

C
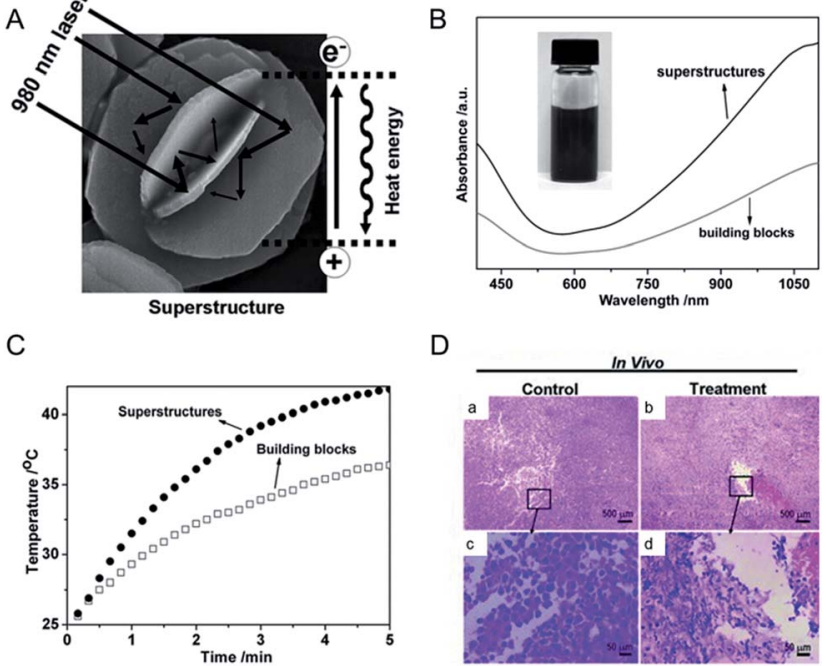

D

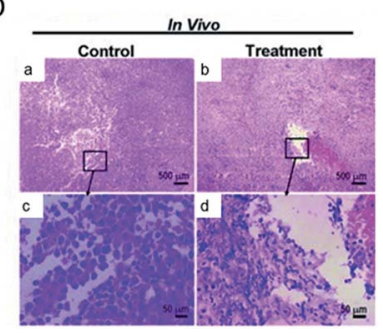

Fig. 2 (A) Schematic representation of a CuS superstructure serving as laser-cavity mirrors for a $980 \mathrm{~nm}$ laser and its photothermal conversion. (B and C) The absorption and temperature elevation of the CuS superstructures and their building blocks, respectively. (D) The representative $\mathrm{H} \& \mathrm{E}$ stained histological images of ex vivo tumor sections treated by water ( $a$ and $c$ ) and CuS superstructure (b and d), respectively. ${ }^{48}$ Reprinted with permission from ref. 49. Copyright 2011 Wiley-VCH Verlag \& Co. KGaA.

increase the obtained heat when using the same amount of nanomaterials. In conclusion, the design direction of constructing a special nanostructure could be divided into two types, the straightforward strategy of the synthesis of the superstructure and the particle-based assembly threedimensional structure. Here, we would illustrate the absorption and therapeutic effect of the CuS superstructure, compared with the normal structure.

3.1.1 CuS superstructure as laser-cavity mirrors. Most of the obtained CuS superstructures are constructed by small building blocks with regular shapes. If the building blocks are aligned with photonic-crystal microstructures and/or the faceted end planes of well-shaped crystals, the synthesized CuS superstructures can be employed as good laser-cavity mirrors, resulting in the promotion of light absorption, ${ }^{73-75}$ which further enhances the PTCE and ultimately improves the therapeutic effects. As in our previous study, ${ }^{48}$ we have designed the novel hydrophilic flower-like CuS superstructures by a one pot hydrothermal route and then demonstrated that CuS superstructures can be employed as an efficient laser-driven photothermal agent, which is promising for the ablation of cancerous cells (Fig. 2A). Most importantly, compared with hexagonal nanoplates (their corresponding building blocks) (Fig. 2B), the as-synthesized CuS superstructure exhibited high absorption intensity especially in the NIR region, which was improved by $50 \%$ of magnitude through constructing photonic-crystal microstructures and/or laser-cavity mirrors that conduced to greatly elevate the absorption and reflection ability for laser, thus offering an improved PTCE as well. Further in our investigations, under the irradiation of a $980 \mathrm{~nm}$ laser with a conservative and safe power density of $0.51 \mathrm{~W} \mathrm{~cm}^{-2}$, CuS

superstructures can efficiently kill cancer cells packaged by chicken skin (Fig. 2C) or in vivo with a short period (5-10 min), consequently showing the superior therapy outcome (Fig. 2D).

By a similar approach, Wu et al. ${ }^{76}$ reported the hollow and hierarchical $\mathrm{CuInS}_{2}$ microspheres, which were constructed separately from the sacrificial templates of solid and hollow CuS microspheres (Fig. 3). The as-synthesized hollow and hierarchical $\mathrm{CuInS}_{2}$ microspheres with close cavities and open cavities, respectively, presented a rosy photothermal conversion effect. To be specific, it is noted that an amount equal to $30 \%$ and $20 \%$ incremental of PTCE was achieved, respectively, mainly attributing to the approach of constructing a special nanostructure. Ground on this intense photothermal conversion effect of the hollow CuS originated from its unique optical property that displayed strong absorption in the NIR region, Samy Ramadan et al. ${ }^{77}$ testified that the permeability of human growth hormone can be increased through disrupting the skin by using the hollow CuS to mediate photothermal ablation. This technique has shown encouraging application in macromolecular drug and vaccine delivery. Therefore, designing a highly meaningful special nanostructure as photothermal conversion agents is supposedly a promising direction for enhancing the PTCE and is further being applied to photothermal ablation therapy.

By assembly of oppositely charged CuS NPs and then calcination at elevated temperature, Tan et al. ${ }^{78}$ have successfully fabricated unique honeycomb-like CuS mesostructures which are composed of densely packed CuS NPs. In this research, based on the intrinsic ability of CuS to absorb light which

A

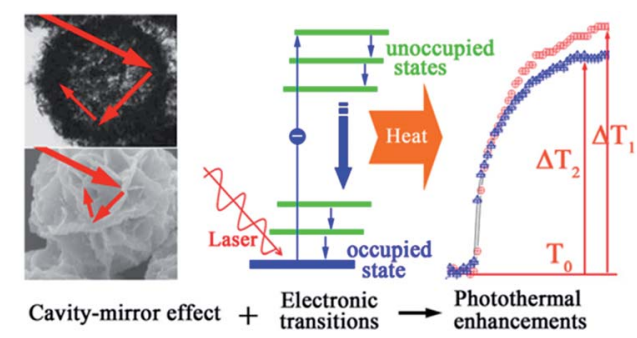

B

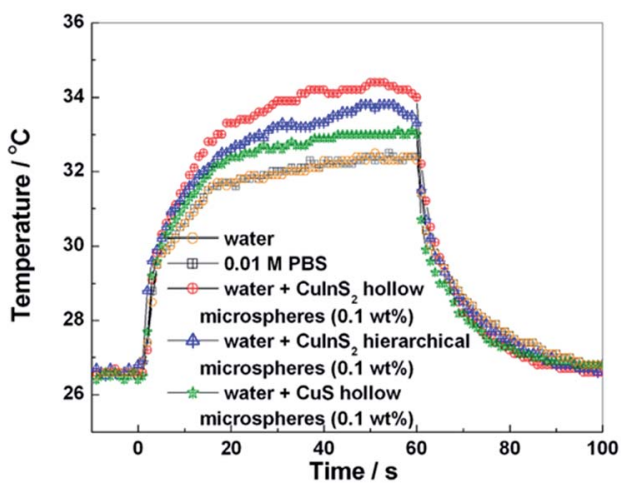

Fig. 3 (A) Schematic demonstration of photothermal conversion enhancement and temperature elevation based on the cavity-mirror effect and interband transitions. (B) Temperature elevation of water, PBS and different superstructures under laser irradiation. ${ }^{76}$ Reprinted with permission from ref. 76. Copyright 2013 American Chemical Society. 
originates from the d-d energy band transition of $\mathrm{Cu}^{2+}$ ions, ${ }^{79}$ the unique honeycomb-like CuS mesoporous nanospheres with high specific surface area ${ }^{\mathbf{8 0} 81}$ can efficiently absorb irradiation light (Fig. 4), leading to enhanced PTCE. As shown in Fig. 4B, under similar irradiation conditions, the $24.4 \%$ PTCE of the CuS mesostructures was proved, compared with their CuS NP precursors, which only displayed $7.5 \%$. Further in vitro experiments (Fig. 4C), when heated in a short time, the CuS mesostructures were able to kill cancerous cells under the irradiation of the NIR laser ( $980 \mathrm{~nm}, 0.51 \mathrm{~W} \mathrm{~cm}^{-2}$ ) in 5 minutes. This result clearly explained that the assembly of CuS greatly improved its capability to absorb light from small particles to big architectures.

\subsection{CuS superstructure with changed electronic structures}

The CuS superstructures in previous reports will exert a great effect on the electronic structures of nanomaterials that can significantly improve the molar extinction coefficient in the NIR region, ${ }^{\mathbf{8 2 , 8 3}}$ which favors energy conversion through the photothermal pathway. In this route, accounting for constructing the superstructure of CuS NPs, the distance of neighboring CuS NPs will shorten, not only allowing for forming new electronic structures of the CuS indirect transition, but also enlarging the entire material near the irradiation absorption cross. Accordingly, improved photothermal performance is therewith realized. Therefore, to be inspiring, this route marks a success on the design and construction of a novel nanostructure and it provides a great kind of potential photothermal therapeutic agent for promoting the development of correlated diagnostic and therapeutic nanotechnologies.

In order to profile the chemism of CuS superstructures that greatly influence the electronic structures, Bu et al. ${ }^{72}$ developed a room-temperature one-pot route to produce water-dispersible shuttle-like CuS superstructures (Fig. 5). In this work, they demonstrated that the shuttle-like CuS superstructures, compared with CuS NPs, can increase the molar extinction

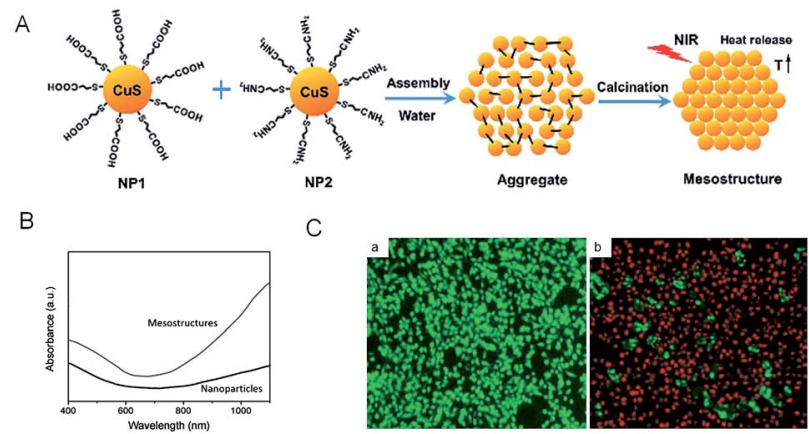

Fig. 4 (A) Schematic illustration of the synthetic procedure of CuS mesostructures. (B) Absorption spectra of the aqueous dispersion of as-synthesized CuS mesostructures and comparable CuS NPs. (C) HeLa cell viability before (a) and after (b) treatment with CuS mesostructures. The living cells were labeled by calcein AM (green emission), and the dead cells were labeled by propidium iodide (red emission). ${ }^{78}$ Reprinted with permission from ref. 78. Copyright 2015 Royal Society of Chemistry.
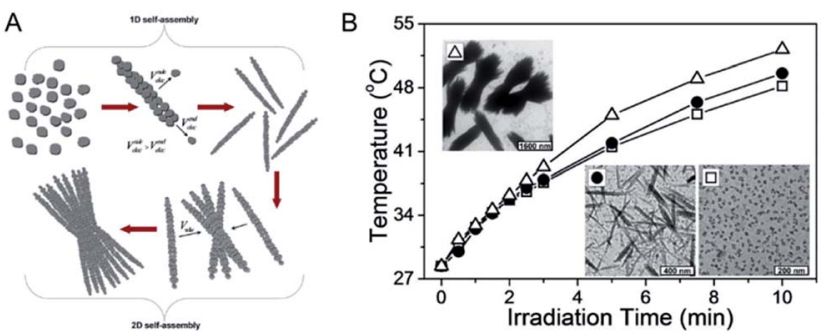

Fig. 5 (A) Schematic illustration of the stepwise self-assembly of CuS NPs to primary nanorods and secondary shuttle-like bundles. (B) Photothermal effect of the aqueous dispersion of CuS NPs (white hollow square), nanorods (black solid round), and bundles (white hollow triangle) under laser irradiation. ${ }^{72}$ Reprinted with permission from ref. 72. Copyright 2014 American Chemical Society.

coefficient up to $9.7 \times 10^{16} \mathrm{~cm}^{-1} \mathrm{M}^{-1}$ through shortening the distance of neighboring CuS NPs. Differing from the small CuS NPs, when in the shuttle-like CuS superstructures, these subbands based on Brillouin zone folding were deduced for the close-packed CuS NPs with specific dipole orientation. ${ }^{\mathbf{8 4}}$ And further, generating such new electronic structures offered strong absorption of CuS nanostructures in the NIR region. Most encouragingly, the study noted that the PTCE of the shuttle-like CuS superstructures was calculated to be $72.6 \%$, with the highest photothermal transduction efficiency among the nanomaterials. ${ }^{85}$ So, it is the electronic structures of the CuS indirect transition that serves as the key determination of optimization for the regular self-assembly structures, which favors energy conversion through a photothermal pathway, further improving NIR laser absorption.

Similarly, in the work of Cui et al., ${ }^{86}$ they demonstrated that the electronic structures would be changed from the nonstoichiometry $\mathrm{Cu}_{7} \mathrm{~S}_{4} \mathrm{NPs}$ to $\mathrm{Cu}_{7} \mathrm{~S}_{4}$ nano-superlattices by both simulation and experiment (Fig. 6). The changed electronic structures will further influence the LSPR, which is closely

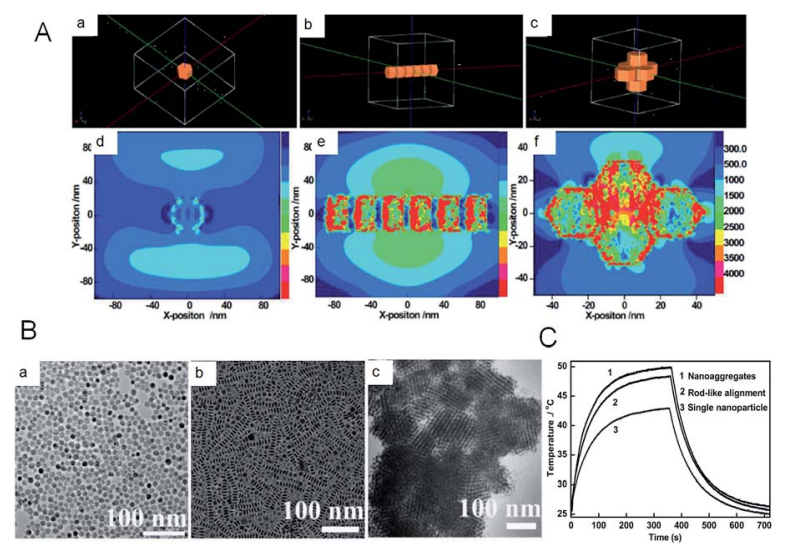

Fig. 6 (A) Simulation of the LSPR for ( $a$, d) single nanoparticles, (b, e) rod-like self-assembly, and (C, f) nanosuperlattices, respectively. (B) TEM images of the prepared nanocomposites. (C) Temperature profiles of obtained nanocomposites irradiated with and without laser ${ }^{86}$ Reprinted with permission from ref. 86. Copyright 2015 WileyVCH Verlag \& Co. KGaA. 
related to the PTCE. Through the simulation of LSPR for the dispersed NPs, rod-like alignments and nano-superlattices, respectively, they first found that the LSPR feature of nanosuperlattices is far stronger than that of dispersed NPs and rod-like alignments, which is highly desirable for a better PTCE (Fig. 6A). And then, to further verify the aforementioned results of the simulation experiment, $\mathrm{Cu}_{7} \mathrm{~S}_{4}$ nano-crystals, the rod-like alignments and self-assembled nano-superlattices were prepared by using partly different reaction parameters. As shown in Fig. 6C, under the identical conditions of illumined laser $\left(1 \mathrm{~W} \mathrm{~cm}^{-2}\right.$ and $\left.808 \mathrm{~nm}\right)$ in a short period, by tuning surface properties of $\mathrm{Cu}_{7} \mathrm{~S}_{4}$ nano-crystals, the PTCE were $48.62 \%$, $56.32 \%, 65.7 \%$ for dispersed NPs, rod-like alignments, and selfassembled nano-superlattices, respectively. Subsequently, the experiments in vitro suggested that these obtained nano-crystals were quite desirable for synergetic photothermal therapy as well. Thus, this research clearly proved that the assembled nanostructure was beneficial to enhance the NIR absorption and PTCE.

\subsection{Non-stoichiometric copper chalcogenide}

LSPRs generally derive from nanostructures of noble metals (such as $\mathrm{Au}, \mathrm{Pd}$ ), ${ }^{34,87}$ rendering a multitude of possibilities to enhance and tune geometrically their absorption and scattering resonances for different ends. Due to the intense LSPRs absorption, the noble metal NPs exhibit good PTCE and have been widely used for photothermal therapy. ${ }^{88}$ But not being limited to that, LSPRs are also available from the semiconductor nano-crystals with appreciable deficiencies that will generate a free carrier concentration. ${ }^{89}$ Differing from the noble metal, whose LSPRs response is permanently locked in and engineered by the choice of nanostructure parameters (such as shape, size, or metal), semiconductor nanostructures could dynamically modulate its LSPRs absorption by doping. The nonstoichiometric copper chalcogenide is exactly one of the typical self-doped semiconductors containing lots of free carriers. As illustrated by Burda et al. ${ }^{90}$ and Luther et al., ${ }^{89}$ nonstoichiometric copper chalcogenide, if its carrier density locates in $10^{19}$ to $10^{22} \mathrm{~cm}^{-3}$, will display a strong absorption in the NIR region, as a result of excess holes in the valence band, ${ }^{89}$ and meanwhile, no absorption is seen for perfectly stoichiometric $\mathrm{Cu}_{2} \mathrm{~S}^{91}$ In addition, not only does copper sulphide nanocrystals possess good absorption characteristics similar to those of metals, but also they present low cost, synthetic simplicity, good photostability, as well as low toxicity, which make them become good potential photothermal agents in nanotechnology photothermal therapeutic platforms. ${ }^{41}$ Therefore, designing and synthesizing non-stoichiometric copper chalcogenide are assumed to be another promising direction for enhancing the PTCE of photothermal agents and for further use in photothermal ablation therapy.

The first example of non-stoichiometric copper chalcogenide serving as a photothermal agent was $\mathrm{Cu}_{2-x} \mathrm{Se}$ NPs reported by Hessel et al. ${ }^{15}$ The obtained $\mathrm{Cu}_{2-x} \mathrm{Se}$ NPs, about $16 \mathrm{~nm}$ coated with an amphiphilic polymer, exhibited a strong NIR absorption in water due to LSPRs (Fig. 7). The molar extinction
A

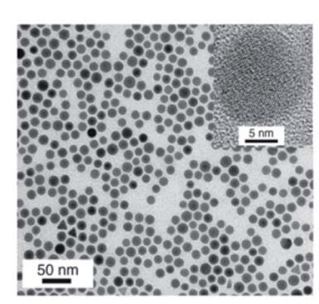

B
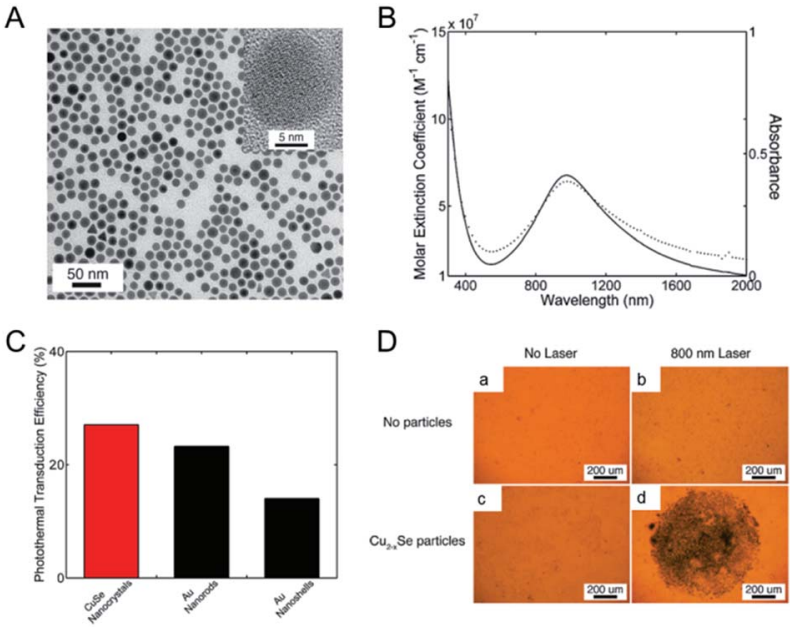

Fig. 7 (A) Typical image of the $\mathrm{Cu}_{2-x} \mathrm{Se}$ NPs. (B) Molar extinction coefficient (solid) and absorption (dot) for the prepared $\mathrm{Cu}_{2-x} \mathrm{Se}$ NPs. (C) Plot of photothermal transduction efficiency for $\mathrm{Cu}_{2-x} \mathrm{Se} \mathrm{NPs,} \mathrm{gold}$ nanorods and gold nanoshells, respectively. (D) Photothermal destruction of HCT-116 cells without ( $a$ and $b$ ) and with (c and d) the $\mathrm{Cu}_{2-x} \mathrm{Se}$ nanocrystals under the irradiation of an $800 \mathrm{~nm}$ laser. The dead cell was stained with trypan blue. ${ }^{15}$ Reprinted with permission from ref. 15. Copyright 2011 American Chemical Society.

coefficient of $\mathrm{Cu}_{2-x}$ Se arrived at a peak of $7.7 \times 10^{7} \mathrm{~cm}^{-1} \mathrm{M}^{-1}$ at $970 \mathrm{~nm}$ and was much higher than the indirect optical transition, which was similar to the gold nanostructure. The strong LSPRs absorption in the NIR region resulted in the higher photothermal transduction efficiency of $\mathrm{Cu}_{2-x} \mathrm{Se}$ NPs (22\%), which was almost as high as Au nanorods (21\%) and obviously higher than Au nanoshells (13\%). Additionally, the significant cell death caused by the photothermal effect of $\mathrm{Cu}_{2-x} \mathrm{Se}$ NPs, confirmed the good potential applications of the nanoparticle agents for photothermal therapy. Therefore, for better use of copper sulphide NPs in photothermal therapy, one of the key determinants is promoting their PTCE by tuning of the LSPR frequency through controlling the self-doping density.

Obviously, the integral absorption intensity is correlated with the characteristic of the material. ${ }^{89}$ In order to generate more $\mathrm{Cu}$ deficiencies, Tian et al. ${ }^{19}$ developed a new photothermal agent (plate-like $\mathrm{Cu}_{9} \mathrm{~S}_{5}$ nano-crystals) on the basis of the thermal decomposition and ligand exchange route (Fig. 8).

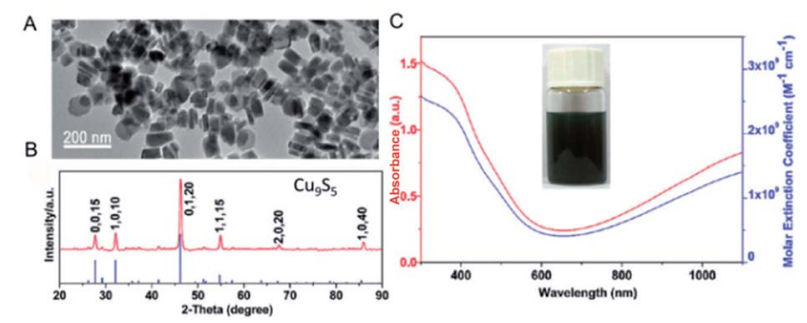

Fig. 8 TEM image (A), and XRD (B), absorption ( $C$, red) and molar extinction coefficient (C, blue) of the prepared $\mathrm{Cu}_{9} \mathrm{~S}_{5} \mathrm{NPs} .{ }^{19}$ Reprinted with permission from ref. 19. Copyright 2011 American Chemical Society. 
On account of LSPR triggered by the p-type carriers, the aqueous dispersion of the prepared $\mathrm{Cu}_{9} \mathrm{~S}_{5}$ NPs exhibited a strong absorption in the NIR region and the calculated molar extinction coefficient at $980 \mathrm{~nm}$ is $\sim 1.2 \times 10^{9} \mathrm{M}^{-1} \mathrm{~cm}^{-1}$, which was similar to the Au nanorods $\left(\sim 1.1 \times 10^{9} \mathrm{M}^{-1} \mathrm{~cm}^{-1}\right)$. The strong NIR absorption also resulted in higher heat conversion efficiency for the $\mathrm{Cu}_{9} \mathrm{~S}_{5}$ nano-crystals $(25.7 \%)$ compared with the $\mathrm{Au}$ nanorods $(23.7 \% \mathrm{~nm}$ laser). Further in vivo experiments demonstrated that the high PTCE of $\mathrm{Cu}_{9} \mathrm{~S}_{5}$ nano-crystals irradiated by a $980 \mathrm{~nm}$ laser at the low and safe power density, made it efficiently kill cancerous cells in 10 minutes. Thus, the enhanced PTCE endowed $\mathrm{Cu}_{9} \mathrm{~S}_{5}$ NPs with the promising potential of being an ideal photothermal agent.

To further improve the PTCE, it is of great importance to tune or enhance the NIR absorption of non-stoichiometric copper chalcogenide. With the same mechanism, several works have been reported to tune the NIR absorption by controlling copper deficiency in the NPs.92,93 For example, through simple oxidation and reduction, the stoichiometric copper chalcogenide and nonstoichiometric counterparts can transform mutually, permitting the dynamic regulation of the degree of copper deficiency in the copper chalcogenide NPs, along with the changing of the LSPRs absorption of copper chalcogenide. ${ }^{93}$ All of these demonstrate that we are able to get higher LSPRs absorption in the NIR region of copper chalcogenide, as well as the higher PTCE, through manipulating the degree of copper deficiency. For this purpose, Li et al. ${ }^{60}$ first reported the preparation of p-type cubic $\mathrm{Cu}_{7.2} \mathrm{~S}_{4}$ NCs with the free holes that induced the LSPR, showing the appearance of broad and extremely strong peaks in the NIR region, as well as 56.7\% PTCE and good photostability when excited by an NIR laser at $980 \mathrm{~nm}$ (Fig. 9). To be noted, the peak position of the achieved $\mathrm{Cu}_{7.2} \mathrm{~S}_{4}$ NCs was tuned to $968 \mathrm{~nm}$ as a consequence of the higher degree of copper deficiency compared with the previously reported $\mathrm{Cu}_{9} \mathrm{~S}_{5}$ NPs, which proved in Luther's study ${ }^{89}$ that the degree of crystal phase can effectively affect and regulate the LSPR spectroscopy. Also, because the maximum
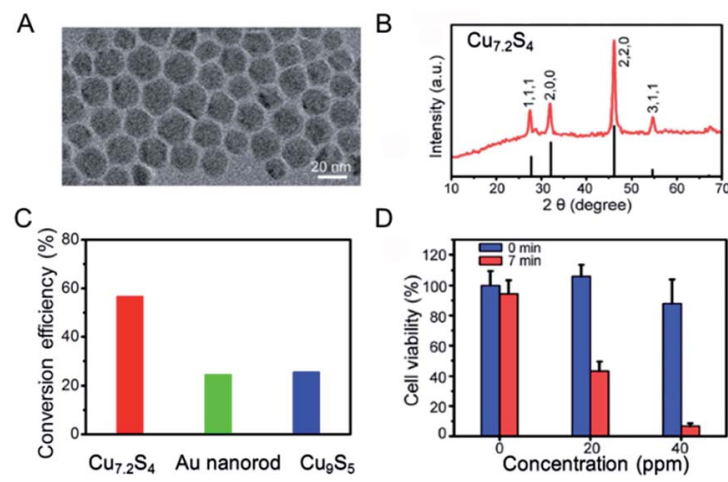

D

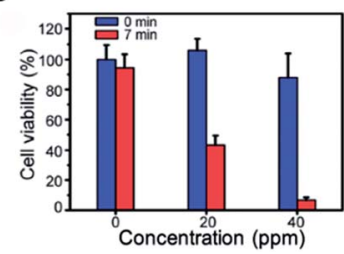

Fig. 9 (A) TEM image and (B) XRD of the obtained $\mathrm{Cu}_{7.2} \mathrm{~S}_{4}$ NPs. (C) Comparison of PTCE for $\mathrm{Cu}_{7.2} \mathrm{~S}_{4}$, gold nanorod and $\mathrm{Cu}_{9} \mathrm{~S}_{5}$ under the irradiation of a $980 \mathrm{~nm}$ laser, respectively. (D) Cell viability after treatment with $\mathrm{Cu}_{7.2} \mathrm{~S}_{4} \mathrm{NPs}$ at different concentration before and after the irradiation of the $980 \mathrm{~nm}$ laser. ${ }^{60}$ Reprinted with permission from ref. 60. Copyright 2014 Royal Society of Chemistry. plasmon resonance absorption wavelength of the assynthesized nano-crystals was tuned by self-doping to be equal to the illumination laser wavelength, the enhanced PTCE of $\mathrm{Cu}_{7.2} \mathrm{~S}_{4}$ nano-crystals was realized, which was higher than that of $\mathrm{Au}$ nanorods, $\mathrm{Cu}_{9} \mathrm{~S}_{5} \mathrm{NCs}, \mathrm{Cu}_{2-x} \mathrm{Se}$ NCs. ${ }^{94}$ More importantly, the obtained $\mathrm{Cu}_{7.2} \mathrm{~S}_{4}$ nano-crystals with higher PTCE were fairly compatible for efficient photothermal ablation therapy both in vitro and in vivo.

\subsection{Copper chalcogenide hybrid nanostructures}

Recently, multifunctional theragnostic agents, based on hybrid nanostructures through conjugating with separate different functional NPs, have attracted extensive attention. ${ }^{95-97}$ These multifunctional photothermal agents can be applied for image contrast and cancer therapy according to the various properties of NPs, including optical and magnetic properties. ${ }^{98-100}$ As an example, our group proposed the ultrasmall (<10 nm) $\mathrm{Fe}_{3} \mathrm{O}_{4} @ \mathrm{Cu}_{2-x} \mathrm{~S}$ core-shell NPs with rational design and a good synthesis method which possess both super paramagnetic properties and high photothermal stability to attain the combined magnetic and optical functionalities. ${ }^{\mathbf{1 0 1}}$ These core-shell NPs not only provided the effective probes for $T_{2}$-weighted magnetic resonance imaging and infrared thermal imaging, but also could be exerted in the further application for photothermal ablation therapy of cancerous cells. However, the PTCE of the obtained core-shell NPs is lower than the previous report of non-stoichiometric copper chalcogenide. Thus, it is important to understand and explain the synergistic effect resulting from the integration of different functional units, to propel the development of the enhanced PTCE of copper chalcogenide.

On account of the collective oscillation of the large amount of hole carriers in the NPs generated from the copper deficiency, the heavily doped copper chalcogenide shows similar LSPRs absorption with the noble metal, in which the intensity and peak for LSPRs absorption are not merely depended on the material, shape, size, and crystalline structure of the noble metal, but also the surrounding environment. ${ }^{102}$ As a consequence, the collective oscillation in the copper chalcogenide will be easily influenced by the surface-enhanced near-field at the noble metal NPs surface, realizing the changed LSPRs absorption and the PTCE. ${ }^{\mathbf{1 0 3}}$ Based on this, Ding et al. ${ }^{\mathbf{1 0 4}}$ reported a dual plasmonic hybrid nanosystem $\mathrm{Au}-\mathrm{Cu}_{9} \mathrm{~S}_{5}$ with well controlled interfaces to investigate the coupling effect of LSPR, determined by the collective electron and hole oscillations (Fig. 10). In their study, the synthesized high-purity $\mathrm{Au}-\mathrm{Cu}_{9} \mathrm{~S}_{5}$ hybrid NPs exhibited a remarkably enhanced LSPR in both visible and NIR regions, and surprisingly achieved $\sim 50 \%$ enhanced absorption at $1064 \mathrm{~nm}$ compared with the Au and $\mathrm{Cu}_{9} \mathrm{~S}_{5}$ NPs when synthesized nearly under the same conditions. Evidently, with the enhanced optical absorption cross section, high photothermal transduction efficiency (37\%) helps Au$\mathrm{Cu}_{9} \mathrm{~S}_{5}$ hybrids to be a kind of robust photothermal agent in the second NIR window with a low nanomaterial concentration versus their individual component $\mathrm{Au}$ and $\mathrm{Cu}_{9} \mathrm{~S}_{5}$ NPs. Therefore, it is a good way to design copper chalcogenide hybrid 
A

C
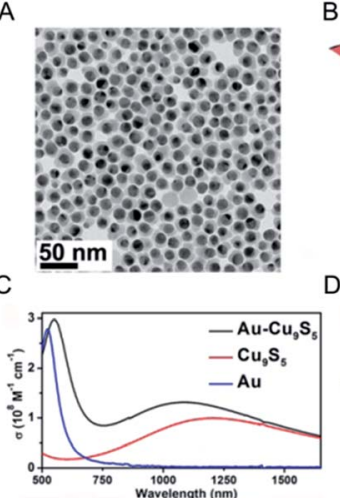

B

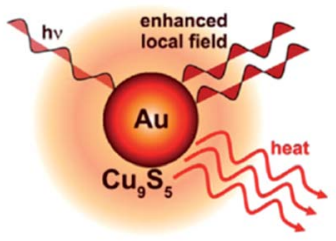

D

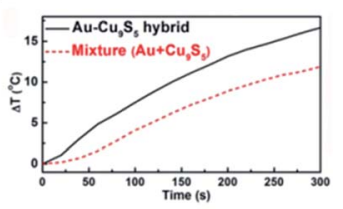

Fig. 10 (A) Typical TEM image of the obtained $\mathrm{Au}-\mathrm{Cu}_{9} \mathrm{~S}_{5}$ hybrid nanostructure. (B) Schematic illustration of a $\mathrm{Au}-\mathrm{Cu}_{9} \mathrm{~S}_{5}$ hybrid to enhance the local field and photothermal performance for $\mathrm{Cu}_{9} \mathrm{~S}_{5}$. (C) LSPRs absorption of the prepared $\mathrm{Au}-\mathrm{Cu}_{9} \mathrm{~S}_{5}$ hybrid nanostructure (black line) compared with the individual components Au (blue line) and $\mathrm{Cu}_{9} \mathrm{~S}_{5} \mathrm{NPs}$ (red line). (D) Photothermal performance for the Au$\mathrm{Cu}_{9} \mathrm{~S}_{5}$ hybrid nanostructure (black solid line) and mixture of $\mathrm{Au}$ and $\mathrm{Cu}_{9} \mathrm{~S}_{5}$ NPs (red dot line). ${ }^{104}$ Reprinted with permission from ref. 104. Copyright 2014 American Chemical Society.

nanostructures with enhanced LSPRs absorption and higher PTCE by utilizing surface plasmon resonance enhancement phenomena.

And latterly, several hybrid nanostructures for copper and gold NPs ${ }^{\mathbf{4 9 , 6 7}}$ were designed and synthesized to demonstrate that the PTCE of the hybrid nanostructures can be apparently enhanced by increased LSPRs absorption, due to the coupling effect of LSPRs caused by the collective oscillations of the electron or hole in the $\mathrm{Au}$ and $\mathrm{Cu}_{2-x} \mathrm{~S}$ NPs. Based on the coupling effect of LSPRs in the hybrid nanostructures and full utilization of light energy by the yolk-shell structure which greatly improves the multiple refractions of light between cores and shells within the interior voids, Zhang et al. ${ }^{67}$ has uncovered the unique $\mathrm{Au} @ \mathrm{Cu}_{7} \mathrm{~S}_{4}$ yolk-shell structure by an inward replacement strategy according to the Kirkendall effect. As expected, the nanomaterials possessed a powerful photothermal performance with 63\% PTCE under the irradiation of $980 \mathrm{~nm}$ light and power density of $0.51 \mathrm{~W} \mathrm{~cm}^{-2}$. Subsequently, Yu et $a l .{ }^{49}$ have further investigated the geometric factors of the hybrid nanostructures acting on their LSPRs absorption and photothermal conversion behavior by using the Au nanorod@ $\mathrm{Cu}_{2-x} \mathrm{~S}$ yolk-shell. They regarded that the thinner shell and smaller inner void showed a stronger surface plasmon resonance absorption and a higher PTCE (Fig. 11). In accordance with the experiment result as well as theory simulation, they explained that the electrical field was closely influenced by the shell thickness and the distance between the inner Au nanorods core and the outer $\mathrm{Cu}_{7} \mathrm{~S}_{4}$ shell. For instance, the electrical field on the surface of the Au nanorods decreased once the $\mathrm{Cu}_{7} \mathrm{~S}_{4}$ shell thickness increased, whereas electrical field intensity around the $\mathrm{Cu}_{7} \mathrm{~S}_{4}$ became obviously stronger, along with the reduction in shell size and also a shorter distance between the $\mathrm{Au}$ nanorod and $\mathrm{Cu}_{7} \mathrm{~S}_{4}$ according to the theory simulation results. Based on this mechanism, the optimum
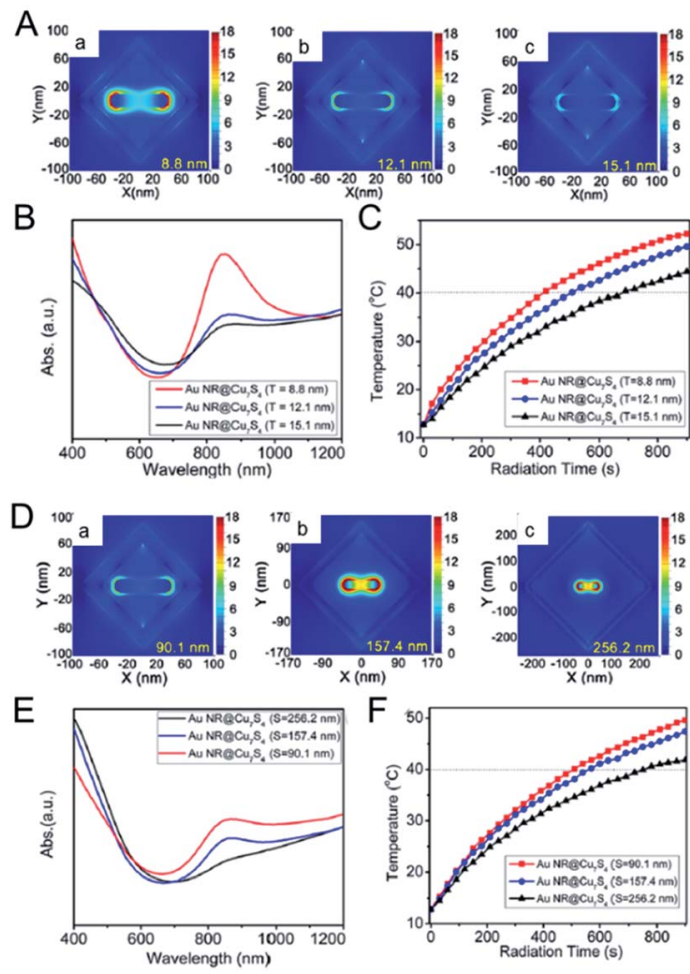

Fig. 11 Electric field distribution of $\mathrm{Au}$ nanorod $\mathrm{aCu}_{7} \mathrm{~S}_{4}$ hybrid with different shell thickness ((A) a, $8.8 \mathrm{~nm} ; \mathrm{b}, 12.1 \mathrm{~nm} ; \mathrm{c}, 15.1 \mathrm{~nm})$ and size ((D) a, $90.1 \mathrm{~nm}$; b, $157.4 \mathrm{~nm}$; $c, 256.2 \mathrm{~nm}$ ) in FDTD simulation. (B, E) The LSPRs absorption spectra and (C, F) photothermal profiles for $A u$ nanorod $\mathrm{CCu}_{7} \mathrm{~S}_{4}$ hybrid with different shell thickness and size. $^{49}$ Reprinted with permission from ref. 49. Copyright 2016 American Chemical Society.

PTCE of yolk-shell NPs could be obtained up to $68.6 \%$. Thus, the design and synthesis of the hybrid nanostructure with the synergistic effect of metal and copper chalcogenide is a highly effective approach to enhance the photothermal property of the copper chalcogenide photothermal agents.

To sum up, these studies for the copper chalcogenide-based composite could be greatly beneficial to the further design of new kinds of hybrid nanostructures that will exhibit superior properties or functions to enhance NIR absorption and improve the PTCE.

\section{Conclusion and outlook}

Over the past few years, the near-infrared laser driven photothermal therapy for cancer based on nanoparticle agents has been of particular interest on the spur of its minimally invasive nature compared with traditional therapy. Amongst the nanoparticle agents, such as gold nanoparticle agents and carbon agents, copper chalcogenide nanoparticle agents have attracted more attention recently due to the low cost and easy preparation. Nevertheless, the underdeveloped PTCE of the copper chalcogenide originally limited their wide application for cancer therapy. In this review, we have discussed three kinds of rational design and mechanisms for copper 
Table 1 A summary of various copper chalcogenide nanoparticles with enhanced photothermal conversion efficiency

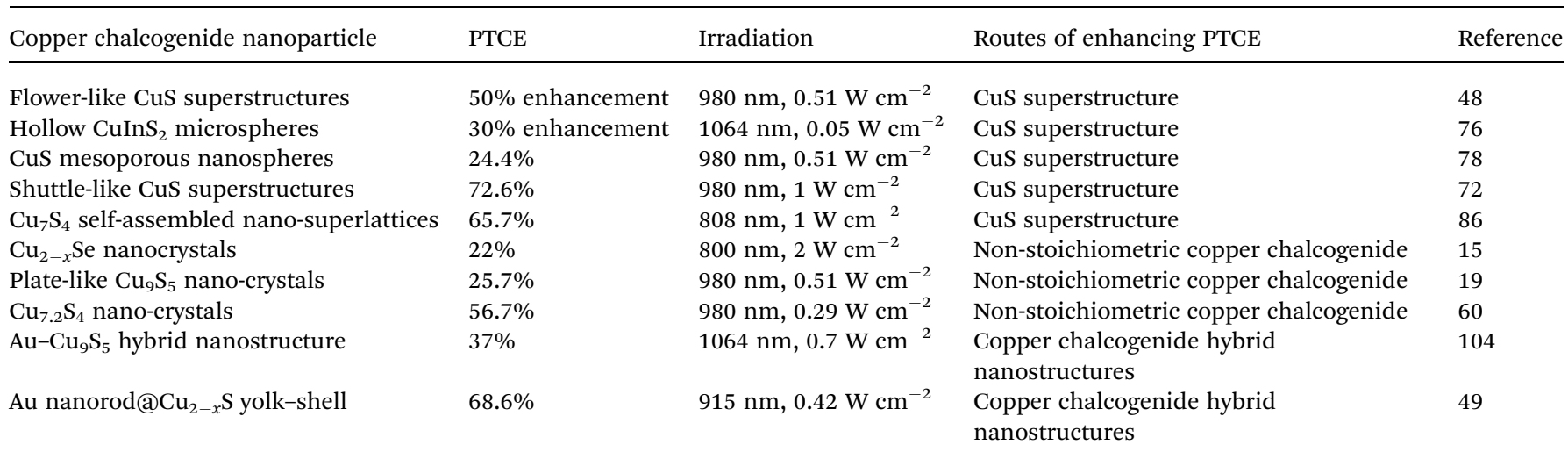

chalcogenide to enhance the heat conversion efficiency in detail and briefly introduced their application in photothermal therapy. First is the design and synthesis of the superstructure nanoparticle agents to enhance photon refraction. Then, tuning the degree of copper deficiency enhances the LSPRs absorption caused by the copper chalcogenide. The rest is constructing the hybrid composite to further enhance the LSPRs absorption through the coupling effect of different functional units. Some typical PTCE of the copper chalcogenide nanoparticles obtained from different design routes are summarized in Table 1 for easy reference. In spite of the higher PTCE and the better treatment effects for cancer that have been achieved by the above three mechanisms, copper chalcogenide nanoparticle agents must be further explored prior to clinical applications.

We believe that copper chalcogenide nanoparticle agents have a bright future and will be adopted in clinical applications, provided that several developments are realized as described below: (i) developing a simple and scalable method to synthesize copper chalcogenide nanoparticle agents with uniform and ultra-small size, good stability and bio-compatibility, (ii) further improving the therapeutic effect with rational design and composition of different functional units, (iii) clearly investigating the side-effect of copper chalcogenide nanoparticle agents on the human body, such as potential long-term toxicity in vivo and the additional barrier(s) that may influence the PTCE at the intact animal (organisms) level. Once such challenging problems are addressed, copper chalcogenide nanoparticle agents will become a widely used theranostics platform for cancer in the future.

\section{Acknowledgements}

This work was partially supported by National Natural Science Foundation of China (No. 21601124 and 21671135), Program of Young Eastern Scholar from Shanghai Institutions of Higher Learning (QD2015038), Shanghai Rising-Star Program (17QA1402600), the Natural Science Foundation of Shanghai (16ZR1424700), Ministry of Education of China (PCSIRT_IRT_16R49), and International Joint Laboratory on Resource Chemistry (IJLRC).

\section{Notes and references}

1 R. L. Siegel, K. D. Miller and A. Jemal, Ca-Cancer J. Clin., 2017, 67, 7-30.

2 K. Pu, A. J. Shuhendler, J. V. Jokerst, J. Mei, S. S. Gambhir, Z. Bao and J. Rao, Nat. Nanotechnol., 2014, 9, 233239.

3 J. Cui, S. Xu, C. Guo, R. Jiang, T. D. James and L. Wang, Anal. Chem., 2015, 87, 11592-11598.

4 X. L. Dean-Ben, S. Gottschalk, B. Mc Larney, S. Shoham and D. Razansky, Chem. Soc. Rev., 2017, 46, 2158-2198.

5 X. Zheng, H. Mao, D. Huo, W. Wu, B. Liu and X. Jiang, Nat. Biomed. Eng., 2017, 1, 0057.

6 C. Chu, H. Lin, H. Liu, X. Wang, J. Wang, P. Zhang, H. Gao, C. Huang, Y. Zeng, Y. Tan, G. Liu and X. Chen, Adv. Mater., 2017, 1605928.

7 C. Zhang, D. Ni, Y. Liu, H. Yao, W. Bu and J. Shi, Nat. Nanotechnol., 2017, 12, 378-386.

8 Z. Zhou, J. Song, L. Nie and X. Chen, Chem. Soc. Rev., 2016, 45, 6597-6626.

9 D. Peer, J. M. Karp, S. Hong, O. C. Farokhzad, R. Margalit and R. Langer, Nat. Nanotechnol., 2007, 2, 751-760.

10 L. Cheng, C. Wang, L. Feng, K. Yang and Z. Liu, Chem. Rev., 2014, 114, 10869-10939.

11 L. Cheng, K. Yang, Y. Li, J. Chen, C. Wang, M. Shao, S.-T. Lee and Z. Liu, Angew. Chem., 2011, 123, 7523-7528.

12 Y. Huang, Y. Lai, S. Shi, S. Hao, J. Wei and X. Chen, Chem.Asian J., 2015, 10, 370-376.

13 R. Weissleder, Nat. Biotechnol., 2001, 19, 316-317.

14 W. R. Chen, R. L. Adams, R. Carubelli and R. E. Nordquist, Cancer Lett., 1997, 115, 25-30.

15 C. M. Hessel, V. P. Pattani, M. Rasch, M. G. Panthani, B. Koo, J. W. Tunnell and B. A. Korgel, Nano Lett., 2011, 11, 2560-2566.

16 Z. Chen, Q. Wang, H. Wang, L. Zhang, G. Song, L. Song, J. Hu, H. Wang, J. Liu, M. Zhu and D. Zhao, Adv. Mater., 2013, 25, 2095-2100.

17 H. Yuan, A. M. Fales and T. Vo-Dinh, J. Am. Chem. Soc., 2012, 134, 11358-11361.

18 X. Huang, P. K. Jain, I. H. El-Sayed and M. A. El-Sayed, Lasers Med. Sci., 2007, 23, 217. 
19 Q. Tian, F. Jiang, R. Zou, Q. Liu, Z. Chen, M. Zhu, S. Yang, J. Wang, J. Wang and J. Hu, ACS Nano, 2011, 5, 97619771.

20 M. Kim, A. Ochirbat and H. J. Lee, Langmuir, 2015, 31, 76097615.

21 H. Rao, W. Sun, S. Ye, W. Yan, Y. Li, H. Peng, Z. Liu, Z. Bian and C. Huang, ACS Appl. Mater. Interfaces, 2016, 8, 78007805.

22 Y. Wu, C. Wadia, W. Ma, B. Sadtler and A. P. Alivisatos, Nano Lett., 2008, 8, 2551-2555.

23 Y. Zhao and C. Burda, Energy Environ. Sci., 2012, 5, 55645576.

24 Z. Li, L. Mi, W. Chen, H. Hou, C. Liu, H. Wang, Z. Zheng and C. Shen, CrystEngComm, 2012, 14, 3965-3971.

25 W. Xu, S. Zhu, Y. Liang, Z. Li, Z. Cui, X. Yang and A. Inoue, Sci. Rep., 2015, 5, 18125.

26 M. Zhou, J. Li, S. Liang, A. K. Sood, D. Liang and C. Li, ACS Nano, 2015, 9, 7085-7096.

27 A. Riedinger, T. Avellini, A. Curcio, M. Asti, Y. Xie, R. Tu, S. Marras, A. Lorenzon, S. Rubagotti, M. Iori, P. C. Capponi, A. Versari, L. Manna, E. Seregn and T. Pellegrino, J. Am. Chem. Soc., 2015, 137, 15145-15151.

28 M. Zhou, R. Zhang, M. Huang, W. Lu, S. Song, M. P. Melancon, M. Tian, D. Liang and C. Li, J. Am. Chem. Soc., 2010, 132, 15351-15358.

29 S. Wang, A. Riedinger, H. Li, C. Fu, H. Liu, L. Li, T. Liu, L. Tan, M. J. Barthel, G. Pugliese, F. De Donato, M. Scotto D'Abbusco, X. Meng, L. Manna, H. Meng and T. Pellegrino, ACS Nano, 2015, 9, 1788-1800.

30 J. T. Robinson, S. M. Tabakman, Y. Liang, H. Wang, H. Sanchez Casalongue, D. Vinh and H. Dai, J. Am. Chem. Soc., 2011, 133, 6825-6831.

31 K. Yang, S. Zhang, G. Zhang, X. Sun, S.-T. Lee and Z. Liu, Nano Lett., 2010, 10, 3318-3323.

32 F. Zhou, S. Wu, B. Wu, W. R. Chen and D. Xing, Small, 2011, 7, 2727-2735.

33 D. Li, D. Han, S.-N. Qu, L. Liu, P.-T. Jing, D. Zhou, W.-Y. Ji, X.-Y. Wang, T.-F. Zhang and D.-Z. Shen, Light: Sci. Appl., 2016, 5, e16120.

34 X. Huang, S. Tang, X. Mu, Y. Dai, G. Chen, Z. Zhou, F. Ruan, Z. Yang and N. Zheng, Nat. Nanotechnol., 2011, 6, 28-32.

35 X. Huang, I. H. El-Sayed, W. Qian and M. A. El-Sayed, J. Am. Chem. Soc., 2006, 128, 2115-2120.

36 J. Song, X. Yang, O. Jacobson, P. Huang, X. Sun, L. Lin, X. Yan, G. Niu, Q. Ma and X. Chen, Adv. Mater., 2015, 27, $4910-4917$.

37 L. Cheng, W. He, H. Gong, C. Wang, Q. Chen, Z. Cheng and Z. Liu, Adv. Funct. Mater., 2013, 23, 5893-5902.

38 Z. Zha, X. Yue, Q. Ren and Z. Dai, Adv. Mater., 2013, 25, 777782.

39 P. Huang, P. Rong, A. Jin, X. Yan, M. G. Zhang, J. Lin, H. Hu, Z. Wang, X. Yue, W. Li, G. Niu, W. Zeng, W. Wang, K. Zhou and X. Chen, Adv. Mater., 2014, 26, 6401-6408.

40 K. Yang, H. Xu, L. Cheng, C. Sun, J. Wang and Z. Liu, Adv. Mater., 2012, 24, 5586-5592.

41 M. Zhou, M. Tian and C. Li, Bioconjugate Chem., 2016, 27, 1188-1199.
42 Z. Wang, A. von dem Bussche, P. K. Kabadi, A. B. Kane and R. H. Hurt, ACS Nano, 2013, 7, 8715-8727.

43 Y. Li, W. Lu, Q. Huang, C. Li and W. Chen, Nanomedicine, 2010, 5, 1161-1171.

44 J. T. Robinson, K. Welsher, S. M. Tabakman, S. P. Sherlock, H. Wang, R. Luong and H. Dai, Nano Res., 2010, 3, 779-793.

45 Z. Chen, L. Zhang, Y. Sun, J. Hu and D. Wang, Adv. Funct. Mater., 2009, 19, 3815-3820.

46 X. Yang, M. Yang, B. Pang, M. Vara and Y. Xia, Chem. Rev., 2015, 115, 10410-10488.

47 S.-W. Hsu, K. On and A. R. Tao, J. Am. Chem. Soc., 2011, 133, 19072-19075.

48 Q. Tian, M. Tang, Y. Sun, R. Zou, Z. Chen, M. Zhu, S. Yang, J. Wang, J. Wang and J. Hu, Adv. Mater., 2011, 23, 35423547.

49 X. Yu, J. Bi, G. Yang, H. Tao and S. Yang, J. Phys. Chem. C, 2016, 120, 24533-24541.

50 P. Roy and S. K. Srivastava, Cryst. Growth Des., 2006, 6, 1921-1926.

51 X.-S. Hu, Y. Shen, L.-H. Xu, L.-M. Wang and Y.-J. Xing, J. Alloys Compd., 2016, 674, 289-294.

$52 \mathrm{~J} . \mathrm{Li}, \mathrm{Q}$. Wu and J. Wu, in Handbook of Nanoparticles, 2015, pp. 1-28.

53 Q. Lu, F. Gao and D. Zhao, Nano Lett., 2002, 2, 725-728.

54 A. Zhang, Q. Ma, M. Lu, G. Zhou, C. Li and Z. Wang, J. Phys. Chem. C, 2009, 113, 15492-15496.

55 W. Bryks, M. Wette, N. Velez, S.-W. Hsu and A. R. Tao, J. Am. Chem. Soc., 2014, 136, 6175-6178.

56 F. Wang, Q. Li, L. Lin, H. Peng, Z. Liu and D. Xu, J. Am. Chem. Soc., 2015, 137, 12006-12012.

57 W. Li, R. Zamani, P. Rivera Gil, B. Pelaz, M. Ibáñez, D. Cadavid, A. Shavel, R. A. Alvarez-Puebla, W. J. Parak, J. Arbiol and A. Cabot, J. Am. Chem. Soc., 2013, 135, 70987101.

58 M. Kruszynska, H. Borchert, A. Bachmatiuk, M. H. Rümmeli, B. Büchner, J. Parisi and J. Kolny-Olesiak, ACS Nano, 2012, 6, 5889-5896.

59 M. B. Sigman, A. Ghezelbash, T. Hanrath, A. E. Saunders, F. Lee and B. A. Korgel, J. Am. Chem. Soc., 2003, 125, 16050-16057.

60 B. Li, Q. Wang, R. Zou, X. Liu, K. Xu, W. Li and J. Hu, Nanoscale, 2014, 6, 3274-3282.

61 C. Wu, S.-H. Yu, S. Chen, G. Liu and B. Liu, J. Mater. Chem., 2006, 16, 3326-3331.

62 Y. Sun and Y. Xia, Adv. Mater., 2003, 15, 695-699.

63 M. Ji, M. Xu, W. Zhang, Z. Yang, L. Huang, J. Liu, Y. Zhang, L. Gu, Y. Yu, W. Hao, P. An, L. Zheng, H. Zhu and J. Zhang, Adv. Mater., 2016, 28, 3094-3101.

64 C.-H. Kuo, Y.-T. Chu, Y.-F. Song and M. H. Huang, Adv. Funct. Mater., 2011, 21, 792-797.

65 C. Dong and F. C. J. M. van Veggel, ACS Nano, 2009, 3, 123130.

66 H. Jin fan, M. Knez, R. Scholz, K. Nielsch, E. Pippel, D. Hesse, M. Zacharias and U. Gosele, Nat. Mater., 2006, 5, 627-631.

67 J. Zhang, G. Liu, F. He, L. Chen and Y. Huang, RSC Adv., 2015, 5, 87903-87907. 
68 E. C. Cho, L. Au, Q. Zhang and Y. Xia, Small, 2010, 6, 517522.

69 L. Y. T. Chou, K. Zagorovsky and W. C. W. Chan, Nat. Nanotechnol., 2014, 9, 148-155.

70 A. Magasinski, P. Dixon, B. Hertzberg, A. Kvit, J. Ayala and G. Yushin, Nat. Mater., 2010, 9, 353-358.

71 S. Guo and S. Sun, J. Am. Chem. Soc., 2012, 134, 2492-2495.

72 X. Bu, D. Zhou, J. Li, X. Zhang, K. Zhang, H. Zhang and B. Yang, Langmuir, 2014, 30, 1416-1423.

73 A. Usami, Chem. Phys. Lett., 1997, 277, 105-108.

74 M. H. Huang, S. Mao, H. Feick, H. Yan, Y. Wu, H. Kind, E. Weber, R. Russo and P. Yang, Science, 2001, 292, 1897.

75 S. Nishimura, N. Abrams, B. A. Lewis, L. I. Halaoui, T. E. Mallouk, K. D. Benkstein, J. van de Lagemaat and A. J. Frank, J. Am. Chem. Soc., 2003, 125, 6306-6310.

76 D. Wu, J. Duan, C. Zhang, K. Guo and H. Zhu, J. Phys. Chem. C, 2013, 117, 9121-9128.

77 S. Ramadan, L. Guo, Y. Li, B. Yan and W. Lu, Small, 2012, 8, 3143-3150.

78 L. Tan, Z. Wu, X. Wang and J. Sun, RSC Adv., 2015, 5, 3531735324.

79 L. Qian, J. Mao, X. Tian, H. Yuan and D. Xiao, Sens. Actuators, B, 2013, 176, 952-959.

80 H. Wu, D. Kong, Z. Ruan, P.-C. Hsu, S. Wang, Z. Yu, T. J. Carney, L. Hu, S. Fan and Y. Cui, Nat. Nanotechnol., 2013, 8, 421-425.

81 A. Corma, P. Atienzar, H. Garcia and J.-Y. Chane-Ching, Nat. Mater., 2004, 3, 394-397.

82 J.-J. Wang, D.-J. Xue, Y.-G. Guo, J.-S. Hu and L.-J. Wan, J. Am. Chem. Soc., 2011, 133, 18558-18561.

83 H. Zhang and D. Wang, Angew. Chem., 2008, 120, 40484051.

84 S. Goel, F. Chen and W. Cai, Small, 2014, 10, 631-645.

85 D. K. Roper, W. Ahn and M. Hoepfner, J. Phys. Chem. C, 2007, 111, 3636-3641.

86 J. Cui, R. Jiang, S. Xu, G. Hu and L. Wang, Small, 2015, 11, 4183-4190.

87 P. Zijlstra, P. M. R. Paulo and M. Orrit, Nat. Nanotechnol., 2012, 7, 379-382.
88 M. S. Yavuz, Y. Cheng, J. Chen, C. M. Cobley, Q. Zhang, M. Rycenga, J. Xie, C. Kim, K. H. Song, A. G. Schwartz, L. V. Wang and Y. Xia, Nat. Mater., 2009, 8, 935-939.

89 J. M. Luther, P. K. Jain, T. Ewers and A. P. Alivisatos, Nat. Mater., 2011, 10, 361-366.

90 S. Link, C. Burda, M. B. Mohamed, B. Nikoobakht and M. A. El-Sayed, J. Phys. Chem. A, 1999, 103, 1165-1170.

91 I. Grozdanov and M. Najdoski, J. Solid State Chem., 1995, 114, 469-475.

92 I. Kriegel, C. Jiang, J. Rodríguez-Fernández, R. D. Schaller, D. V. Talapin, E. da Como and J. Feldmann, J. Am. Chem. Soc., 2012, 134, 1583-1590.

93 D. Dorfs, T. Härtling, K. Miszta, N. C. Bigall, M. R. Kim, A. Genovese, A. Falqui, M. Povia and L. Manna, J. Am. Chem. Soc., 2011, 133, 11175-11180.

94 H. Chen, L. Shao, T. Ming, Z. Sun, C. Zhao, B. Yang and J. Wang, Small, 2010, 6, 2272-2280.

95 C. Sun, M. Liu, Y. Zou, J. Wei and J. Jiang, RSC Adv., 2016, 6, 26374-26379.

96 X. Wang, C. Wang, L. Cheng, S.-T. Lee and Z. Liu, J. Am. Chem. Soc., 2012, 134, 7414-7422.

97 J. Bai, Y. Liu and X. Jiang, Biomaterials, 2014, 35, 5805-5813. 98 Q. Tian, Q. Wang, K. X. Yao, B. Teng, J. Zhang, S. Yang and Y. Han, Small, 2014, 10, 1063-1068.

99 K. Yang, L. Hu, X. Ma, S. Ye, L. Cheng, X. Shi, C. Li, Y. Li and Z. Liu, Adv. Mater., 2012, 24, 1868-1872.

100 L.-S. Lin, X. Yang, Z. Zhou, Z. Yang, O. Jacobson, Y. Liu, A. Yang, G. Niu, J. Song, H.-H. Yang and X. Chen, Adv. Mater., 2017, 29, 1606681.

101 Q. Tian, J. Hu, Y. Zhu, R. Zou, Z. Chen, S. Yang, R. Li, Q. Su, Y. Han and X. Liu, J. Am. Chem. Soc., 2013, 135, 8571-8577.

102 R. Jiang, B. Li, C. Fang and J. Wang, Adv. Mater., 2014, 26, 5274-5309.

103 X. Liu, C. Lee, W.-C. Law, D. Zhu, M. Liu, M. Jeon, J. Kim, P. N. Prasad, C. Kim and M. T. Swihart, Nano Lett., 2013, 13, 4333-4339.

104 X. Ding, C. H. Liow, M. Zhang, R. Huang, C. Li, H. Shen, M. Liu, Y. Zou, N. Gao, Z. Zhang, Y. Li, Q. Wang, S. Li and J. Jiang, J. Am. Chem. Soc., 2014, 136, 15684-15693. 